\title{
Ecology of Sand Flies (Diptera: Psychodidae: Phlebotominae) in the North of the State of Mato Grosso, Brazil
}

\author{
Alfredo CR Azevedo/ ${ }^{+}$, Nataly A Souza, Cláudio RV Meneses, Wagner A Costa, \\ Simone M Costa, José B Lima*, Elizabeth F Rangel
}

Laboratório de Transmissores de Leishmanioses, Departamento de Entomologia, Instituto Oswaldo Cruz-Fiocruz, Av. Brasil 4365, 21045-900 Rio de Janeiro, RJ, Brasil *Instituto de Biologia do Exército, Rio de Janeiro, RJ, Brasil

Peixoto de Azevedo is located in the north of State of Mato Grosso, where environmental alterations led to an outbreak of American cutaneous leishmaniasis in the 80s. The parasite from patients was characterized as Leishmania (V.) braziliensis. The aim of this study is to contribute to the sand fly ecology of Central-West Brazil. Captures were carried out monthly using CDC light traps. Twenty-six species of sand fly were characterized; among which Lutzomyia (Lutzomyia) spathotrichia, L. runoides and L. (Psychodopygus) llanosmartinsi were recorded in the State of Mato Grosso for the first time. L. (Nyssomyia) whitmani, L. (N.) antunesi, L. (L.) spathotrichia, L. (P.) c. carrerai, L. (P.) complexa, L. (P.) lainsoni and L. (N.) umbratilis constituted $92.4 \%$ of the local fauna, among which L. (N.) whitmani and L. (N.) antunesi, accounting for about 53\% of the fauna at the stations of capture. On the vertical distribution of sand flies on the Beira-Rio Farm, L. (N.) whitmani and L. (N.) antunesi prevailed at ground level and in the canopy, respectively, whereas on the BR-080, L. (P.) llanosmartinsi was prevalent on the ground and $\mathrm{L}$. (P.) c. carrerai, in the canopy. It is suggested that L. (N.) umbratilis is the local vector.

Key words: Lutzomyia umbratilis - Leishmania braziliensis - Phlebotominae - Mato Grosso - Brazil

Environmental alterations in different regions of Brazil have been modifying the epidemiological profile of leishmaniasis for some decades. These changes have created high-risk areas for Leishmania infection (Lainson 1988, 1989, Walsh et al. 1993, Rangel 1995).

The migration movements toward the Amazon Region that have taken place in the last three decades have been directly or indirectly supported by the Federal Government through colonization projects and road construction. Those migratory currents have produced considerable alterations in the environment and they have given rise to haphazard colonization models. Such environmental changes and new associations between man and nature have created new focuses of human disease: malaria and, especially of cutaneous leishmaniasis. Peixoto de Azevedo country, in the north of the State of Mato Grosso, is an area where such a chain of events has been recorded.

The region was covered by primitive forest 25 years ago, but now there are over 100,000 inhabitants in the area, and their main interests have been agriculture and mining. These two activities account for the regions thriving economy followed by wood extraction and cattle raising. The economic development of the region has contributed to the changing in the environment and has brought the population into contact with vector sand flies and could explain the increase in the number of cases of

Research conducted with the support of Faperj/RJ, CNPq, and Fiocruz, Brazil.

${ }^{+}$Corresponding author: Fax:+55-21-2573.4468 E-mail: alcaraze@ioc.fiocruz.br

Received 5 June 2001

Accepted 7 January 2002 cutaneous leishmaniasis from of the mid-80s, according to data supplied by the Health National Foundation, Cuiabá, State of Mato Grosso. In the region, the disease manifests as a single ulcerated lesion, together with smaller or multiple ulcerated lesions.

Preliminary studies have revealed the presence of the sand fly vectors L. (Nyssomyia) whitmani, L. (N.) umbratilis and L. (N.) flaviscutellata (Rangel et al. 1998a) not only in the forest but also in the miners' camping areas and in domestic animal shelters. Both $L$. (N.) umbratilis and L. (Psychodopygus) davisi were found naturally infected by trypanosomatids, prossibly Leishmania that belong to the Peripilaria section (Lima et al. 1997). The parasite found in L. (N.) umbratilis was later characterized as L. (Viannia) braziliensis (T Pereira, pers. commun.).

This study aims to contribute to present knowledge on phlebotomine sand fly ecology the in the Central-West Region of Brazil.

\section{MATERIALS AND METHODS}

Area studied - Peixoto de Azevedo, a large country covering an area of $14,383 \mathrm{~km}^{2}$ is located $661 \mathrm{~km}$ from Cuiabá, in the north of the State of Mato Grosso, at latitude 10'13'23'S and longitude 54'58'47'W (Fig. 1). The weather is hot and humid, with three dry months (equatorial climate), with an average yearly temperature of $26^{\circ} \mathrm{C}$, and annual rainfall ranging from 2,000 to $3,000 \mathrm{~mm}$. The relief of the area presents a complex base made up of southern Amazon Plateau Residuals. Those plateaus, that interfluves with slopes at heights above $400 \mathrm{~m}$ are included in the Peripheral Amazon Basin, which also features mountain ridges carved in volcanic, sub-volcanic and metamorphic Precambrian rocks. The local vegetation is composed by an ecologically tense region, a small spot where two different vegetation types occur (Ama- 


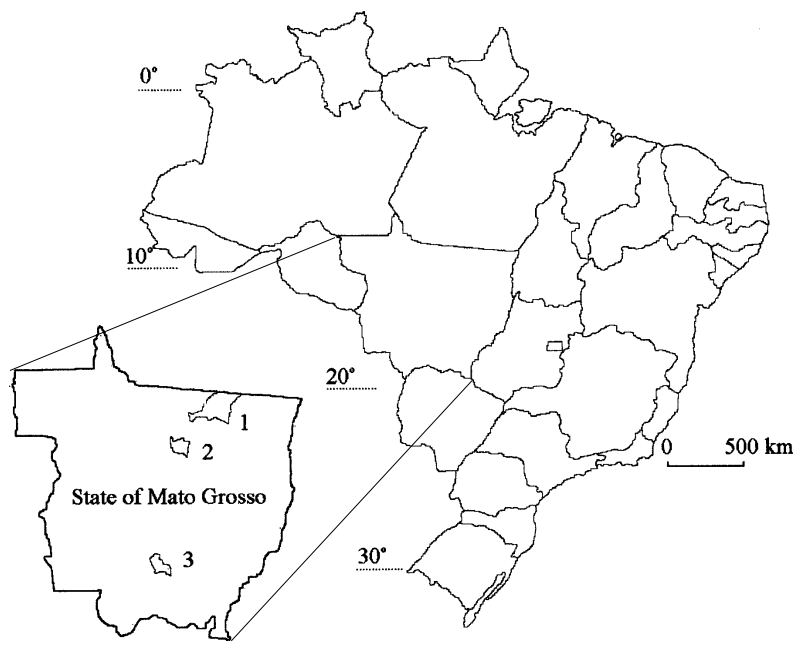

Fig. 1: municipality of Peixoto de Azevedo, State of Mato Grosso, Brazil. 1: Peixoto de Azevedo; 2: Sinop; 3: Cuiabá

zon Forest and savanna) (IBGE 1996). This region has been influenciated by human modifications (anthropic action). The local economy now is based on agricultural production (rice, corn, beans), cattle raising, timber extraction (cinnamon, jatobá and cedar), and lately, in less proportion on gold prospecting.

Sand fly collections - In order to establish the two collection sites, some captures with Shannon trap were done. The station Beira-Rio Farm was approximately 22 $\mathrm{km}$ apart from station BR-080 (primary Forest). Sand fly collections were carried out monthly between 6:00 p.m. and 6:00 a.m. from May 1997 to October 1998. The captures were made at the tree canopy $(18 \mathrm{~m})$, at an intermediate level $(10 \mathrm{~m})$ and near the ground $(50 \mathrm{~cm})$ by means of CDC light traps (Sudia \& Chamberlain 1962).

Species identification - The sand flies were preserved in $70 \%$ alcohol, and later processed for mounting between slide and cover glass, with the use of Canada balsam. The species identification was made according to the classification adopted by Young and Duncan (1994).

The index of species abundance (ISA) (Roberts \& His 1971) was applied in order to evaluate the abundance of species of Peixoto de Azevedo.

\section{RESULTS}

Species identification - Twenty six phlebotomine species were identified at the two collection stations: Brumptomyia brumpti (Larrousse) 1920, Lutzomyia (Lutzomyia) spathotrichia Martins, Falcão \& Silva 1963, L. (Sciopemyia) sordellii (Shannon \& Del Ponte 1927), L. migonei (França 1920), L. sericea (Floch \& Abonnenc 1944), L. wilsoni (Damasceno \& Causey 1945), L. (Viannamyia) furcata (Mangabeira 1941), L. (Psathyromyia) campbelli (Damasceno, Causey \& Arouck 1945), L. (P.) dendrophyla (Mangabeira 1942), L. runoides (Fairchild \& Hertig 1953), L. aragaoi (Costa Lima 1932), L. hermanlenti Martins, Silva \& Falcão 1970, L. (Trichopygomyia) dasypodogeton (Castro 1939), L.
(T.) rondonensis Martins, Falcão \& Silva 1965, L. (Nyssomyia) flaviscutellata (Mangabeira 1942), L. (N.) antunesi (Coutinho 1939), L. (N.) whitmani (Antunes \& Coutinho 1939), L. (N.) umbratilis Ward \& Fraiha 1977, L. (N.) yuilli yuilli Young \& Porter 1972, L. (Psychodopygus) lainsoni (Fraiha \& Ward 1974), L. (P.) complexa (Mangabeira 1941), L. (P.) davisi (Root 1934), L. (P.) llanosmartinsi (Fraiha \& Ward 1980), L. (P.) hirsuta hirsuta (Mangabeira 1942), L. (P.) ayrozai (Barretto \& Coutinho 1940), L. (P.) carrerai carrerai (Barretto 1946). Among the species listed, L. (L.) spathotrichia, L. runoides and $L$. (P.) llanosmartinsi are mentioned in the State of Mato Grosso for the first time. A total number of 6,449 specimens were collected, of which, L. (N.) whitmani, L. (N.) antunesi, L. (P.) llanosmartinsi, L. (P.) c. carrerai, L. (P.) complexa, L. (P.) lainsoni and L. (N.) umbratilis accounted for $92.4 \%$ of the local fauna. $L$. (N.) whitmani (ISA $=4.5$ ) and $L .(N$.) antunesi $(\mathrm{ISA}=4.8$ ) were the most abundant species, accounting for $53.5 \%$ of the total (Table I).

Sand fly distribution per collecting area - A qualitative difference between sand fly species was observed when the collections from the two different stations were compared. Nineteen and 21 species were identified on the Beira-Rio Farm and at the BR-080 stations, respectively. Some species were exclusively detected at the BR080 station: L. runoides, L. (T.) dasypodogeton, L. (T.)

\section{TABLE I}

Total, percentage and index of species abundance (ISA) of sand flies collected in Peixoto de Azevedo, State of Mato Grosso, Brazil, May 1997/October 1998

\begin{tabular}{lrrrrr}
\hline Species & Male & Female & Total & \% & ISA \\
\hline Brumptomyia brumpti & 19 & 5 & 24 & 0.4 & 10.9 \\
Lutzomyia spathotrichia & 1 & 3 & 4 & 0.1 & 15.3 \\
L. sordellii & 14 & 1 & 15 & 0.2 & 15.3 \\
L. migonei & 10 & 6 & 16 & 0.2 & 15.3 \\
L. sericea & 28 & 26 & 54 & 0.8 & 9.6 \\
L. wilsoni & 4 & 1 & 5 & 0.1 & 15.8 \\
L. furcata & 2 & 1 & 3 & 0 & 16.6 \\
L. campbelli & - & 1 & 1 & 0 & 17.3 \\
L. dendrophyla & - & 1 & 1 & 0 & 17.3 \\
L. runoides & 6 & - & 6 & 0.1 & 16.8 \\
L. aragaoi & 26 & 14 & 40 & 0.6 & 12.1 \\
L. hermanlenti & 84 & 40 & 124 & 1.9 & 8.7 \\
L. dasypodogeton & 11 & 2 & 13 & 0.2 & 15.1 \\
L. rondonensis & 2 & 4 & 6 & 0.1 & 16.8 \\
L. flaviscutellata & 2 & - & 2 & 0 & 17.0 \\
L. antunesi & 400 & 768 & 1,168 & 18.1 & 4.8 \\
L. whitmani & 1,777 & 507 & 2,284 & 35.4 & 4.5 \\
L. umbratilis & 261 & 112 & 373 & 5.8 & 6.7 \\
L. y. yuilli & 6 & 1 & 7 & 0.1 & 15.3 \\
L. lainsoni & 81 & 328 & 409 & 6.3 & 7.8 \\
L. complexa & 59 & 470 & 529 & 8.2 & 8.6 \\
L. davisi & 89 & 55 & 144 & 2.2 & 10.0 \\
L. llanosmartinsi & 224 & 392 & 616 & 9.6 & 10.0 \\
L. h. hirsuta & 11 & 4 & 15 & 0.2 & 16.3 \\
L. ayrozai & 4 & 3 & 7 & 0.1 & 17.3 \\
L. c. carrerai & 33 & 550 & 583 & 9 & 10.0 \\
\hline Total & 3,154 & 3,295 & 6,449 & 100 & \\
\hline & & & & &
\end{tabular}


rondonensis, $L$. (N.) y. yuilli, $L$. (P.) llanosmartinsi, $L$. (P.) h. hirsuta and $L$. (P.) ayrozai. Some other species were only detected on the Beira-Rio Farm: $L$. (L.) spathotrichia, $L$. (S.) sordellii, $L$. (V.) furcata, $L$. (P.) campbelli, $L$. (P.) dendrophyla and $L$. (N.) flaviscutellata (Table II). The species of the Nyssomyia sub-genus had a higher incidence on the Beira-Rio Farm (94.2\%), and at that station the prevailing species, accounting for $67 \%$ of the total of specimens collected, was $L$. (N.) whitmani (Fig. 2A). The Psychodopygus sub-genus was prevalent at BR-080 (71.3\%), of which $L$. (P.) llanosmartinsi, $L .(P$. c. carrerai, $L$. (P.) complexa and $L$. (P.) lainsoni represented $92.8 \%$ (Fig. 2B).

Sand fly stratification - As regards the seven species of highest occurrence it was observed that $L$. (N.) whitmani, $L$. (N.) antunesi and $L$. (N.) umbratilis were found at three different levels on the Beira-Rio Farm. There $L$. (N.) whitmani was prevalent on the ground $(96.5 \%)$ and at $10 \mathrm{~m}(45.8 \%)$, while $L$. (N.) antunesi was found much more frequently in the canopy (48.3\%) (Fig. 3A). On the BR-080, the seven species mentioned above were found on the three levels: $L$. (P.) llanosmartinsi was prevalent on the ground (29\%) and at $10 \mathrm{~m}(38.7 \%)$, while $L$. $(P$.) c. carrerai was more frequently found in the canopy $(20.1 \%)$ and, among the least numerous species, the presence of $L$. (P.) davisi on the ground (11.7\%) is remarkable (Fig. 3B).

L. (N.) umbratilis was the seventh most abundant species, accounting for $5.7 \%$ of the specimens collected at both stations. The $L$. (N.) umbratilis captures were productive at the intermediate level $(10 \mathrm{~m})$ and in the canopy, where the total of specimens from the two levels totalled 94\% (Beira-Rio Farm) and 98\% (BR-080) (Fig. 4).
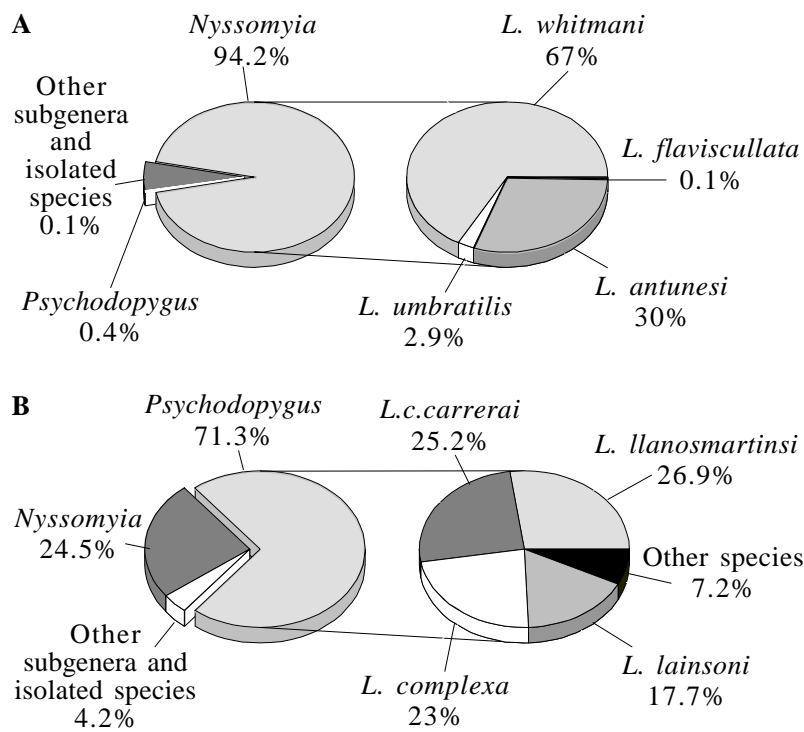

Fig. 2: the frequencies of the sub-genera Nyssomyia and Psychodopygus and the predominant sand fly species. Peixoto de Azevedo, State of Mato Grosso, Brazil (1997-1998). A: Beira-Rio Farm; B: BR-080

\section{DISCUSSION}

Peixoto de Azevedo is a municipality that has been undergoing a high level of environmental degradation over the years, as it has seen a remarkable increase in its population especially in areas where housing conditions favour the emergence of cutaneous leishmaniasis. The occupational disease profile seems to be well evident in the region, as most of the people affected work in agriculture and mining.

The light trap CDC type has been systematically used in studies on sand flies in forest areas and/or in areas where there is leishmaniasis transmission (Arias \& Freitas 1982, Aguiar et al. 1985a, Gomes \& Galati 1987, Dourado et al. 1989, Azevedo \& Rangel 1991, Azevedo et al. 1993, Galati et al. 1996, Brazil et al. 2000, Barros et al. 2000). In spite of the fact that this kind of collection does not allow access to the great number of species, which may constitute the local fauna (Shaw \& Lainson 1972) when undertaken at different capture sites, this type of collection can yield a representative sample of the sand fly fauna in a given area.

Located in the southern Amazon Basin, Peixoto de Azevedo has sand fly fauna characteristic of the Amazon Region. Species that belong to the Brumptomyia, Lutzomyia genera (seven sub-genera) and six isolated species totalled 26. Except for $L$. (L.) spathotrichia, $L$. runoides and $L$. (P.) llanosmartinsi, the other species had already been registered in the State of Mato Grosso (EAB Galati \& AL Falcão, pers. commun., Martins et al. 1978, Young \& Duncan 1994).

The contrasts between preserved and modified areas in the region studied became evident when the sand fly fauna was qualitatively analyzed. The species distribution per collection and per stratified area showed variations according to the alterations that had taken place in the vegetation where the two collecting stations were located. The BR-080 station is located in an area where the environmental degradation rate is lower and the vegetation is typical of the southern Amazon Region. On the other hand, the area where the Beira-Rio Farm is located has been systematically exploited by different economic activities.

Studies of stratification in forested areas have made the description of phlebotomine feeding habits possible. Their preference for mammals whose habitat are on the ground or at canopy level has contributed with information about the different cycles of leishmaniasis transmission. In the primary Amazonian forest in the North of Brazil, the species of Psychodopygus and Nyssomyia prevail, on the ground and in the tree canopy, respectively (Arias \& Freitas 1982, Azevedo et al. 1993). But this trend was not observed in Peixoto de Azevedo, for on the Beira-Rio Farm, Nyssomyia was prevalent on the ground and $L$. (N.) whitmani and $L$. (N.) antunesi, in the canopy. At BR080, Psychodopygus was predominant, whereas $L$. (P.) llanosmartinsi had the highest rate on the ground and $L$. (P.) c. carrerai, in the canopy. This evidence may can corroborate the existence of a qualitative and quantitative imbalance in the regional phlebotomine fauna.

Among the local sand fly fauna, some species are referred to by Young and Duncan (1994) and Lainson and 
TABLE II

Total and percentage of sand flies on Beira-Rio Farm and BR 080 in Peixoto de Azevedo, State of Mato Grosso, Brazil, May 1997/October 1998

\begin{tabular}{|c|c|c|c|c|c|c|c|c|}
\hline \multirow[b]{2}{*}{ Species } & \multicolumn{4}{|c|}{ Beira-Rio Farm } & \multicolumn{4}{|c|}{ BR-080 } \\
\hline & Males & Females & Total & $\%$ & Males & Females & Total & $\%$ \\
\hline Brumptomyia brumpti & 16 & 4 & 20 & 0.6 & 3 & 1 & 4 & 0.1 \\
\hline Lutzomyia spathotrichia & 1 & 3 & 4 & 0.1 & - & - & - & - \\
\hline L. sordellii & 14 & 1 & 15 & 0.5 & - & - & - & - \\
\hline L. migonei & 1 & 6 & 7 & 0.2 & 9 & - & 9 & 0.3 \\
\hline L. sericea & 7 & 14 & 21 & 0.6 & 21 & 12 & 33 & 1 \\
\hline L. wilsoni & 4 & - & 4 & 0.1 & - & 1 & 1 & 0 \\
\hline L. furcata & 2 & 1 & 3 & 0.1 & - & - & - & - \\
\hline L. campbelli & - & 1 & 1 & 0.1 & - & - & - & - \\
\hline L. dendrophyla & - & 1 & 1 & 0 & - & - & - & - \\
\hline L. runoides & - & - & - & - & 6 & - & 6 & 0.2 \\
\hline L. aragaoi & 1 & - & 1 & 0 & 25 & 14 & 39 & 1.2 \\
\hline L. hermanlenti & 76 & 23 & 99 & 3.1 & 8 & 17 & 25 & 0.8 \\
\hline L. dasypodogeton & - & - & - & - & 11 & 2 & 13 & 0.4 \\
\hline L. rondonensis & - & - & - & - & 2 & 4 & 6 & 0.2 \\
\hline L. flaviscutellata & 2 & - & 2 & 0.1 & & & & 0 \\
\hline L. antunesi & 326 & 587 & 913 & 28.2 & 74 & 181 & 255 & 7.9 \\
\hline L. whitmani & 1,599 & 443 & 2,042 & 63.1 & 178 & 64 & 242 & 7.5 \\
\hline L. umbratilis & 67 & 22 & 89 & 2.8 & 194 & 90 & 284 & 8.8 \\
\hline L. y. yuilli & - & - & - & - & 6 & 1 & 7 & 0.2 \\
\hline L. lainsoni & 1 & 2 & 3 & 0.1 & 80 & 326 & 406 & 12.6 \\
\hline L. complexa & 3 & - & 3 & 0.1 & 56 & 470 & 526 & 16.4 \\
\hline L. davisi & 1 & 1 & 2 & 0.1 & 88 & 54 & 142 & 4.4 \\
\hline L. llanosmartinsi & - & - & - & - & 224 & 392 & 616 & 9.2 \\
\hline L. h. hirsuta & - & - & - & - & 11 & 4 & 15 & 0.5 \\
\hline L. ayrozai & - & - & - & - & 4 & 3 & 7 & 0.2 \\
\hline L. c. carrerai & 2 & 3 & 5 & 0.2 & 31 & 547 & 578 & 18 \\
\hline Total & 2,123 & 1,112 & 3,235 & 100 & 1,031 & 2,183 & 3,214 & 100 \\
\hline
\end{tabular}

Shaw (1998) as having been naturally infected by Leishmania, with special emphasis on the vectorial importance of $L$. (N.) flaviscutellata and $L$ (N.) umbratilis, in the North, L. (N.) whitmani, in the North, Northeast and Southeast and Psychodopygus species (L. (P.) complexa) in the North of Brazil.

L. (N.) flaviscutellata was found in low densities; and only collected on the Beira-Rio Farm. Having a nocturnal habit and being not very anthropophilic, it has been suggested that it is the vector of $L$. (L.) amazonensis, responsible for the anergic diffuse clinical form of tegumentary leishmaniasis in the Amazon Region. Apparently, this phlebotomine is not involved in the local leishmaniasis ecology at the two collecting station in Peixoto de Azevedo.

L. (N.) whitmani was present at both collecting stations; however, its density was lower at BR-080, than on the Beira-Rio Farm, where species of the sub-genus Nyssomyia prevailed.

The relationship between the primary forest and the density of the Psychodopygus species has also been observed in Bolivia (Le Pont \& Desjeux 1986) and in Brazil (Biancardi et al. 1982, Aguiar \& Soucasaux 1984, Aguiar et al. 1985b, Ready et al. 1986).

The highest density of the Nyssomyia species and especially of L. (N.) whitmani may be associated with modifications in the original vegetation cover and because of a better adaptation to the new environmental conditions.

Epidemiological study of cutaneous leishmaniasis carried out in the Corguinho, State of Mato Grosso do Sul (Nunes et al. 1995) isolated parasites identified as L. (V.) braziliensis in patients and Galati et al. (1996) have suggested $L$. (N.) whitmani as the likely vector, considering that this phlebotomine was found to be naturally infected by flagellate protozoan whose behaviour was similar that of the parasite mentioned and was also the most abundant species at almost all the different ecological sites where the captures were made. L. (N.) whitmani is often associated with the peridomicile in the cutaneous leishmaniasis transmission area in the Northeastern and Southeastern Regions of Brazil (Cuba-Cuba et al. 1985, Azevedo \& Rangel 1991). In these regions the human population is concentrated on the hill slopes, which have often lost of their original vegetation cover due to the continuous sustenance agriculture. However, in Peixoto de Azevedo, this sand fly presents a behaviour pattern more similar to that observed of the population of the Northern Brazilian region, with sylvatic habits and not inclined to bite human being. 
$L$. (N.) umbratilis is considered to be the main vector of $L$. (V.) guyanensis, responsible for most cases of cutaneous leishmaniasis in the Amazon Region. Studies on the stratification of this phlebotomines in the Northern region in Brazil have shown that its density is as high in the canopy as on the ground, where specimens can be collected right on the tree trunks and also during their anthropophilic activity in the first hours of daylight. They also feed on human blood at dusk (Arias \& Freitas 1982, Lainson 1983, Ready et al. 1986).
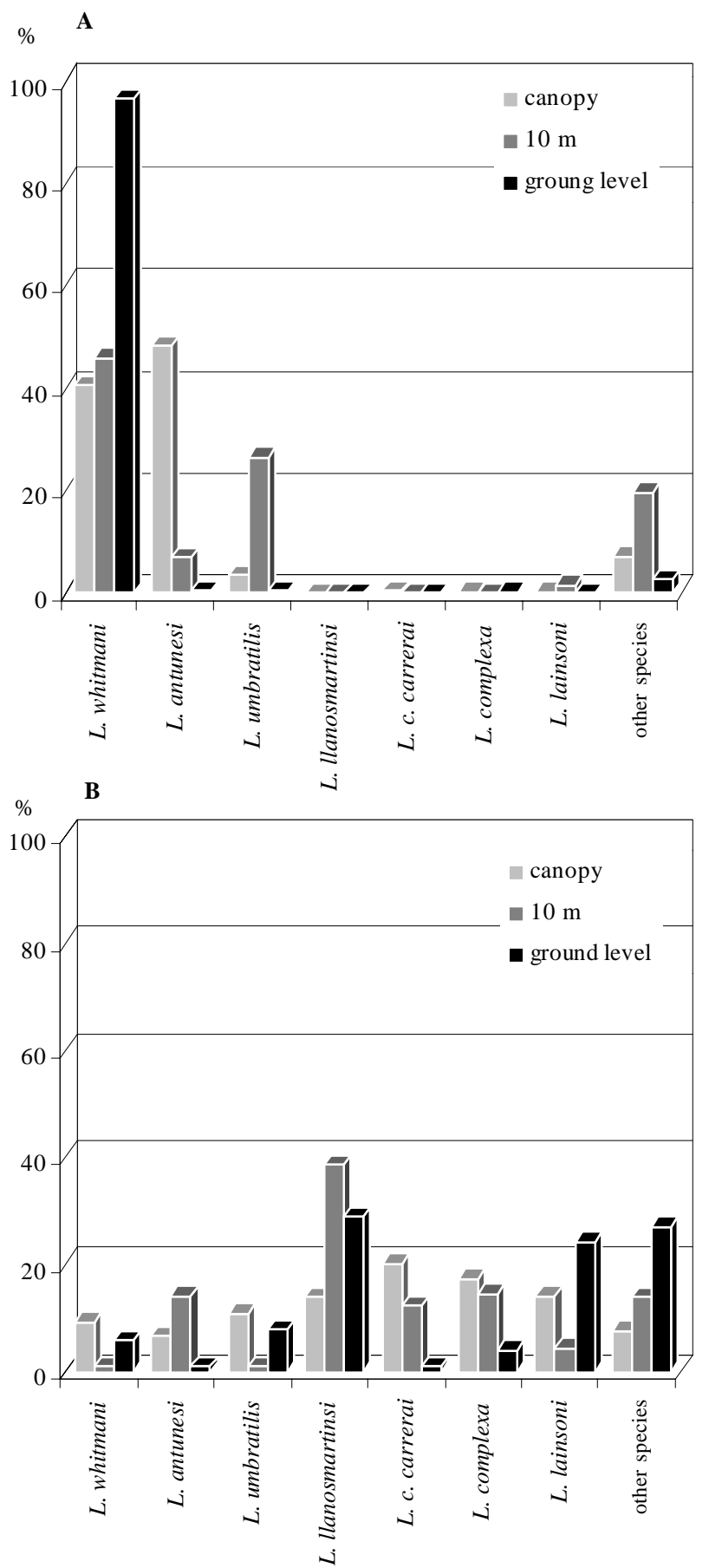

Fig. 3: stratification of predominant sand fly species from both captures stations. Peixoto de Azevedo, State of Mato Grosso, Brazil (1997-1998). A: Beira-Rio Farm; B: BR-080

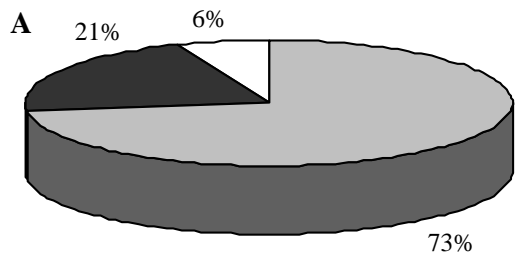

$\square$ canopy $\square 10 \mathrm{~m} \square$ ground level

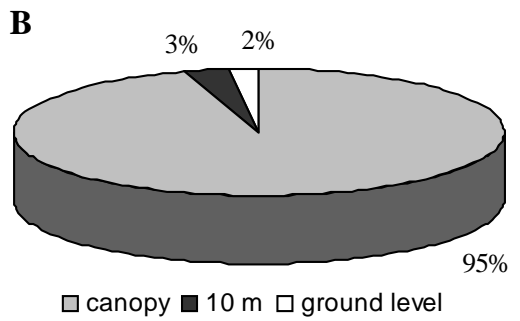

Fig. 4: stratification of Lutzomyia (N.) umbratilis at both captures stations. Peixoto of Azevedo, State of Mato Grosso, Brazil (19971998). A: Beira-Rio Farm; B: BR-080

In Peixoto de Azevedo, L. (N.) umbratilis was found at both stations, however, the BR-080 station showed the highest number of collected specimens $(76.1 \%) . L .(N)$ umbratilis was the most abundant species at the intermediate level and in the canopy of trees. Our observations confirm the habit of this species coexisting preferably in the canopy of threes. The same findings were previously described in the Amazonian region (Arias \& Freitas 1982, Azevedo et al. 1993).

Previous studies on natural infection made in Peixoto de Azevedo have demonstrated a possible association of that phlebotomine with $L$. (V.) braziliensis, the same parasite that has been isolated from patients. Tissue samples from the borders of lesions were inoculated into the feet of hamsters. After development of the papulae, the material was transported and cultivated in enriched blood-agar medium (NNN) for Leishmania. One isolate was characterized as $L$. (V.) braziliensis by enzymatic profiles, using reference stocks of $L$. (V.) braziliensis, $L$. (V.) guyanensis and $L$. (V.) amazonensis (Rangel et al. 1998b). This suggests that $L$. (N.) umbratilis may be a local vector, bearing in mind that the use of the Shannon trap in some of the collections permitted the detection of degree of anthropophily for this specie (EF Rangel, pers. commun.).

Bearing in mind Lainson's hypothesis (1988) that $L$. (N.) umbratilis only infects $L$. (V.) guyanensis in the north of the River Amazon, this new evidence suggests the existence of a complex of species. It may also be admitted that genetically heterogeneous populations could also be associated with different cycles of leishmaniasis transmission in Brazil.

\section{ACKNOWLEDGEMENTS}

To Maria de Fátima Barros and Temísio Pereira, Instituto de Biologia do Exército, Rio de Janeiro, RJ, Brazil; Dr Steve Orosko, Walter Reed Army Institute, USA and the Fundação 
Nacional de Saúde, Brazil, for their cooperation during the field work for this project and Dr Elisa Cupolillo, Instituto Oswaldo Cruz for text revision.

\section{REFERENCES}

Aguiar GM, Soucasaux T 1984. Aspectos da ecologia dos flebótomos do Parque Nacional da Serra dos Órgãos, Rio de Janeiro. I. Freqüência mensal em isca humana (Diptera, Psychodidae, Phlebotominae). Mem Inst Oswaldo Cruz 79: 197209.

Aguiar GM, Schuback PA, Vilela ML, Azevedo ACR 1985b. Aspectos da ecologia dos flebótomos do Parque Nacional da Serra dos Órgãos, Rio de Janeiro. Distribuição vertical (Diptera, Psychodidae, Phlebotominae). Mem Inst Oswaldo Cruz 80: 187-194.

Aguiar GM, Vilela ML, Schuback PA, Soucasaux T, Azevedo ACR 1985a. Aspectos da ecologia dos flebótomos do Parque Nacional da Serra dos Órgãos, Rio de Janeiro. IV. Frequiência mensal em armadilhas (Diptera, Psychodidae, Phlebotominae). Mem Inst Oswaldo Cruz 80: 465-482.

Arias JR, Freitas RA 1982. On the vectors of cutaneous leishmaniasis in the Central Amazon of Brazil. 3. Phlebotomine sand fly stratification in a terra firme florest. Acta Amazônica 12: 599-608.

Azevedo ACR, Rangel EF 1991. A study of sandfly species (Diptera: Psychodidae: Phlebotominae) in a focus of cutaneous leishmaniasis in the municipality of Baturité, Ceará State, Brazil. Mem Inst Oswaldo Cruz 86: 405-410.

Azevedo ACR, Bessa-Luz S, Vilela ML, Rangel EF 1993. Studies on the sandfly fauna of Samuel Ecological Station, Porto Velho municipality, Rondônia State, Brazil. Mem Inst Oswaldo Cruz 88: 509-512.

Barros VLL, Rebêlo JMM, Silva FS 2000. Flebotomíneos (Diptera: Psychodidae) de capoeira do município de Paço Lumiar, Estado do Maranhão, Brasil. Área de transmissão de leishmaniose. Cad Saúde Publ 16: 265-270.

Biancardi CB, Arias JR, Freitas RA, Castellon EG 1982. The known geographical distribution of sand flies in the state of Rondônia, Brazil (Diptera: Psychodidae). Acta Amazônica 12: 167-179.

Brazil RP, Andrade Filho D, Falcão AL 2000. Notes on phlebotomine sand flies (Diptera: Psychodidae) from Amapá State, North Brazil. J Am Mosq Contr Assoc 16: 40-41.

Cuba-Cuba CA, Miles MA, Vexenat A, Barker DC, Mc Mahon Pratt D, Butcher J, Barreto AC, Marsden PH 1985. A focus of mucocutaneous leishmaniasis in Três Braços, Bahia, Brazil: Characterization and identification of Leishmania stocks isolated from man and dogs. Trans R Soc Trop Med Hyg 79: 500-507.

Dourado MIC, Noronha CV, Alcântara N, Ichihara MY, Loureiro $\mathrm{S}$ 1989. Epidemiologia da leishmaniose tegumentar americana e suas relações com a lavoura e o garimpo, em localidade do Estado da Bahia (Brasil). Rev Saúde Publ 23: 2-8.

Galati EA, Nunes VLB, Dorval MEC, Oshiro ET, Cristaldo G, Espíndola MA, Rocha HC, Garcia NB 1996. Estudos dos flebotomíneos (Diptera: Psychodidae), em área de leishmaniose tegumentar, no Estado de Mato Grosso do Sul, Brasil. Rev Saúde Públ 30: 115-128.

Gomes AC, Galati AB 1987. Aspectos ecológicos da leishmaniose tegumentar americana. 5. Estratificação da atividade espacial e estacional de Phlebotominae (Diptera: Psychodidae) em áreas de cultura agrícola da região do Vale do Ribeira, Estado de São Paulo, Brasil. Mem Inst Oswaldo Cruz 82: 467-473.

IBGE-Instituto Brasileiro de Geografia e Estatística 1996. Anuário Estatístico do Brasil, Departamento Editoriação Gráfica/ DEDIT/ CDDI, IBGE, Rio de Janeiro, 8/32 pp.
Lainson R 1983. The American leishmaniasis: some observations on their ecology and epidemiology. Trans $R$ Soc Trop Hyg 77: 569-596.

Lainson R 1988. Ecological interactions in the transmission of the leishmaniasis. Phil Trans $R$ Soc Lond B 321: 389-404.

Lainson R 1989. Demographic changes and their influence on the epidemiology of the American cutaneous leishmaniases. In Michael W Service, Demography and Vector Borne Diseases, CRC Press, Florida, p. 85-106.

Lainson R, Shaw JJ 1998. New World leishmaniasis - The Neotropical Leishmania species. In L Collier, A Baeows, M Sussman (eds), Microbiology and Microbial Infections, Vol. 5, p. 241-266.

Le Pont F, Desjeux P 1986. Leishmaniasis in Bolivia. II. The involvement of Psychodopygus yucumensis and Psychodopygus llanosmartinsi in the selvatic transmission cycle of Leishmania braziliensis braziliensis in a lowland subandean region. Mem Inst Oswaldo Cruz 81: 311-318.

Lima JBP, Pereira TR, Grogl M, Quintana M, Hohosko S 1997. Detection of Leishmania from phlebotomine in a cutaneus leishmaniasis endemic area of Mato Grosso, Brasil. Men Inst Oswaldo Cruz, 92(Suppl. I ): 320.

Martins AV, Williams P, Falcão AL 1978. American Sand Flies, Academia Brasileira de Ciência, Rio de Janeiro, 195 pp.

Nunes VLB, Dorval MEC, Oshiro ET, Noguchi RC, Arão LB, Hans Filho G, Espíndola MA, Cristaldo G, Rocha HC, Serafini LN, Santos D 1995. Estudo epidemiológico sobre leishmaniose tegumentar (LT) no município de Corguinho, Mato Grosso do Sul - Estudos na população humana. Rev Soc Bras Med Trop 28: 185-193.

Rangel EF 1995. Transmission on American cutaneous leishmaniasis in peridomestic foco in Rio de Janeiro State and other similar situation comparing with the classic epidemiology in Amazon region. Seminar Trop Disease, Society and Environment, WHO/TDR, Technical report.

Rangel EF, Azevedo ACR, Orosko S, Lima JB, Souza NA, Pereira T, Meneses CRV, Costa W, Cupollilo E, Brahim L 1998b. Lutzomyia (Nyssomyia) umbratilis (Ward \& Fraiha, 1977) and the ecology of Americam cutaneous leismaniasis in Mato Grosso state. I Bienal de Pesquisa da Fundação Oswaldo Cruz, p. 122

Rangel EF, Orosko S, Lima JB, Souza NA, Pereira T, Meneses C, Cupolillo E, Brahim L 1998a. Epidemiologia da leishmaniose cutânea no norte do Estado de Mato Grosso, Brasil. XXXIV Congresso da Sociedade Brasileira de Medicina Tropical, p. 132

Ready PD, Lainson R, Shaw JJ, Ward RD 1986. The ecology of Lutzomyia umbratilis Ward \& Fraiha (Diptera: Psychodidae), the major vector to man of Leishmania braziliensis guyanensis in north-easther Amazonia, Brazil. Bull Ent Res 76: 21-40.

Roberts DR, Hsi BP 1979. An index of species abundance for use with mosquito surveillance data. Environ Entomol 8: 1007-1013.

Shaw JJ, Lainson R 1972. Leishmaniasis in Brazil: VI. Observations on the seasonal variations of Lutzomyia flaviscutellata in different types of florest and its relationship to enzootic rodent leishmaniasis (Leishmania mexicana amazonensis). Trans $R$ Soc Trop Med Hyg 66: 709-717.

Sudia WD, Chamberlaim RN 1962. Battery operated light traps an improved model. Mosquito News 22: 126-129.

Walsh JF, Molyneux DH, Birley MH 1993. Deforestation: effects on vector-borne disease. Parasitology 106: 55-75.

Young DG, Duncan MA 1994. Guide to the identification and geographic distribution of Lutzomyia sandflies in Mexico, the West Indies, Central and South America (Diptera: Psychodidae). Mem Amer Ent Inst 54: 1-881. 